\title{
PENGARUH KEBIJAKAN PEMERIKSAAN, KEBIJAKAN AKSES INFORMASI KEUANGAN DAN FORENSIK DIGITAL TERHADAP KUALITAS PEMERIKSAAN PAJAK
}

\section{Luh Putu Dian Shavitri Handayani dan Gede Sri Darma}

Universitas Pendidikan Nasional (UPN) Veteran Jawa Timur, Indonesia

Email: shavitri.dian@gmail.com dan sridarma@undiknas.ac.id

\section{Abstract}

This research aims to obtain empirical evidence of the influence of the implementation of priority targeting policy inspection, policy open account for taxation and digital forensic interests on the quality of examination in the Regional Office of DJP Bali. The approach used is quantitative approach using purposive sampling method in sample determination and Partial Least Square (PLS) method as data analysis technique. The results indicate that the policy of targeting the priority of examination, account opening policy and digital forensics have a positive and significant influence on the quality of examination. Indonesia's tax ratio is still relatively low, indicating that there is still a lot of tax potential that has not been unearthed, so the results of this study are expected to make a meaningful contribution to policymakers and tax authorities in order to implement appropriate strategies to improve the quality of inspections so as to increase the willingness to pay from taxpayers.

Keywords: priority target of inspection; open an account; digital forensics; inspection quality

\begin{abstract}
Abstrak
Penelitian ini bertujuan untuk mendapatkan bukti empiris pengaruh implementasi kebijakan penentuan sasaran prioritas pemeriksaan, kebijakan buka rekening untuk kepentingan perpajakan dan forensic digital terhadap kualitas pemeriksaan di Lingkungan Kanwil DJP Bali. Pendekatan yang digunakan adalah pendekatan kuantitatif dengan menggunakan metode purposive sampling dalam penentuan sampel dan metode Partial Least Square (PLS) sebagai teknik analisis data. Hasil penelitian mengindikasikan bahwa kebijakan penentuan sasaran prioritas pemeriksaan, kebijakan buka rekening dan forensic digital memberikan pengaruh yang positif dan signifikan terhadap kualitas pemeriksaan. Tax ratio Indonesia yang masih tergolong rendah, menandakan masih banyak potensi pajak yang belum tergali, sehingga hasil penelitian ini diharapkan dapat memberikan kontribusi berarti bagi pembuat kebijakan dan otoritas pajak agar dapat mengimplementasikan strategi yang sesuai untuk meningkatkan kualitas pemeriksaan sehingga dapat meningkatkan kemauan membayar dari wajib pajak.
\end{abstract}

Kata kunci: sasaran prioritas pemeriksaan; buka rekening; forensik digital; kualitas pemeriksaan 


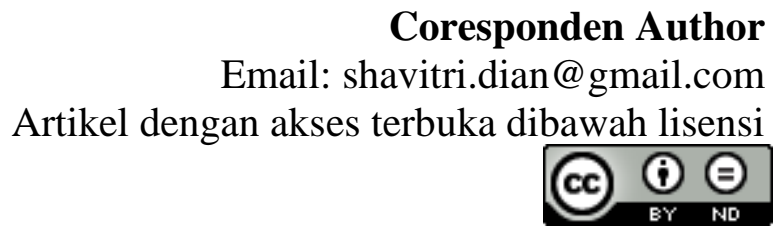

\section{Pendahuluan}

Melakukan pengawasan terhadap wajib pajak dalam memenuhi kewajiban perpajakannya secara self-assessment (Republik Indonesia, 2007) melalui kegiatan pemeriksaan pajak merupakan hal yang esensial, karena merupakan salah satu bentuk alat penegakan hukum untuk menentukan keberhasilan penerimaan pajak, hal ini sejalan dengan hasil penelitian oleh (Aspexsia, 2018), (Mebratu, 2016), (Palil \& Mustapha, 2011), (Asnawi, 2013), namun berbeda dengan hasil penelitian oleh Modugu dan Anyaduba (2014), dimana pemeriksaan pajak belum berpengaruh terhadap pemenuhan pajak di Nigeria. Terkait kebijakan perpajakan, berdasarkan penelitian oleh (George \& Diavastis, 2015) diperoleh hubungan negatif antara undang-undang pajak dan pelacakan pelanggaran pajak, namun berdasarkan laporan OECD (2006) dan penelitian oleh (D’Agosto et al., 2018), undang-undang hukum memegang peranan penting bagi kinerja pemeriksa pajak. Oleh karena itu, sejalan dengan reformasi birokrasi yang sedang dijalankan oleh Direktorat Jenderal Pajak dan kebutuhan akan penyempuraan dalam kegiatan pemeriksaan, telah dilakukan penetapan terhadap beberapa kebijakan dalam rangka mendukung kegiatan pemeriksaan pajak yang berkualitas dengan bukti kompeten yang dapat diandalkan, diantaranya kebijakan mengenai penentuan sasaran prioritas pemeriksaan dengan kriteria yang telah ditetapkan melalui implementasi dari Surat Edaran Dirjen Pajak nomor 15 tahun 2018 tentang Kebijakan Pemeriksaan (Direktorat Jenderal Pajak, 2018), penetapan Perpu Nomor 1 Tahun 2017 Tentang Akses Informasi Keuangan untuk Kepentingan Perpajakan, dimana Direktur Jenderal Pajak berwenang mendapatkan akses informasi keuangan untuk kepentingan perpajakan ke lembaga jasa keuangan, lembaga jasa keuangan lainnya, dan/atau entitas lain, sehingga kegiatan pemeriksaan dapat dilaksanakan dengan lebih optimal karena telah tersedianya akses yang luas bagi direktorat jenderal pajak untuk memperoleh informasi keuangan wajib pajak, dalam pembentukan basis data perpajakan yang lebih kuat dan akurat (Pemerintah Republik Indonesia, 2017). Selain itu, perkembangan teknologi informasi dan komunikasi mengakibatkan semakin banyak wajib pajak yang memanfaatkan teknologi digital, baik dalam menjalankan proses bisnisnya maupun dalam melakukan pengolahan data. Hal ini memungkinkan segala aktivitas pencatatan data transaksi keuangan dan non-keuangan dapat terdokumentasi secara digital (paperless), dimana terdapat hubungan kuat antara investasi dalam teknologi informasi dengan performa usaha (Darma, 2006) (Lo \& Darma, 2000), dengan demikian upaya pengawasan dan penegakan hukum tidak mampu lagi menggunakan cara konvensional, sehingga sebagai upaya penegakan hukum tersebut ditetapkan Surat Edaran Direktur 
Jenderal Pajak nomor 36 tahun 2017 tentang Pedoman Forensik Digital untuk Kepentingan Perpajakan (Direktorat Jenderal Pajak, 2017).

Berdasarkan penjelasan dan research gap diatas, penelitian ini ingin menganalisis dan memberikan bukti secara empiris apakah implementasi dari kebijakan penentuan sasaran prioritas pemeriksaan, kebijakan akses informasi keuangan untuk kepentingan perpajakan dan forensik digital memberikan pengaruh terhadap kualitas pemeriksaan.

\section{Metode Penelitian}

Pendekatan yang digunakan dalam penelitian ini adalah pendekatan kuantitatif. Penelitian ini dilaksanakan di Lingkungan Kanwil DJP Bali. Data primer dalam penelitian ini diperoleh dari pengisian kuesioner terkait Surat Perintah Pemeriksaan (SP2) terhadap wajib pajak yang diperiksa, yang akan diisi oleh pemeriksa pajak di lingkungan Kanwil DJP Bali. Populasi sasaran dalam penelitian ini adalah data SP2 berdasarkan Daftar Sasaran Priotitas Pemeriksaan yang terbit per akhir Oktober 2019 yaitu sebanyak 260 SP2. Adapun teknik sampling yang digunakan adalah teknik non-probability sampling yaitu purposive sampling. Berdasarkan tabel penentuan jumlah sampel dari populasi tertentu oleh (Sugiyono, 2011), untuk tingkat kesalahan 10\%, dengan jumlah populasi 260 diperlukan 133 jumlah sampel. Jumlah sampel dalam penelitian ini adalah 136 sampel. Jawaban setiap pertanyaan menggunakan skala semantik differensial 1-10 yang memiliki kategori dari yang sangat tidak setuju sampai dengan yang sangat setuju.

Variabel independen dalam penelitian ini adalah implementasi kebijakan penentuan sasaran prioritas pemeriksaan pajak (SSP), implementasi kebijakan buka rekening untuk kepentingan perpajakan (BUREK), dan pelaksanaan forensik digital (FD) sedangkan variabel dependen adalah kualitas pemeriksaan (KUAL). Teknik analisis data yang digunakan adalah Partial Least Square (PLS). Analisis data melalui PLS dalam penelitian ini dibagi menjadi dua bagian yaitu pengujian model (outer model) yang meliputi uji validitas dan uji reliabilitas dan evaluasi model struktural (inner model).

\section{Hasil dan Pembahasan}

Pada proses awal, sebelum masuk dalam pengukuran inner model (hubungan antar variabel laten), akan dilakukan pengujian terlebih dahulu terhadap reliabilitas meliputi uji Indicator Reliability dan Internal Consistency Reliability dan uji validitas meliputi uji validitas konvergen dan uji validitas diskriminan dari outer model-nya, yang akan dilakukan dengan menggunakan Aplikasi SmartPLS (v.3.2.8).

Uji Indicator reliability dapat diketahui melalui nilai outer loadings. Semakin tinggi nilai outer loadings artinya semakin tinggi korelasi antara variabel laten dan indikatornya atau semakin tinggi sebuah variabel laten dapat menjelaskan varian indikator dalam model pengukuran reflektif. Nilai outer loadings diharapkan lebih besar dari 0.7 , nilai minimum outer loadings yang dapat diterima dalam riset eksploratori adalah 0.4 (Ken Kwong-Kay Wong, 2013). Jika nilai outer loadings $<0.4$, indikator 
tersebut dapat dipertimbangkan untuk dieliminasi, namun dengan memperhatikan, eliminasi dari indikator tersebut dapat meningkatkan nilai composite reliability-nya (Henseler et al., 2009). Berdasarkan hasil pada tabel 1, 15 indikator telah memenuhi indicator reliability dengan nilai $>0.4$, terdapat 1 indikator memiliki nilai outer loadings yang tidak memenuhi nilai minimum yang dapat diterima yaitu indikator BUREK2 dengan nilai outer loadings 0.296 , nilai outer loadings tersebut $<0.4$, sehingga indikator BUREK2 tersebut dapat dipertimbangkan untuk dieliminasi. Setelah dilakukan eliminasi terhadap indikator BUREK2 diketahui bahwa terjadi peningkatan composite realibility yang lebih baik yaitu dari 0.774 menjadi 0.830 (tabel 2 dan 3).

Tabel 1

Nilai outer loadings dari tiap indikator dalam penelitian

\begin{tabular}{lccc}
\hline \multicolumn{5}{c}{ X1(SPP) } & X2(BUREK) & X3 (FD) & Y1(KUAL) \\
\hline SPP1 & 0.893 & & \\
\hline SPP2 & 0.838 & & \\
\hline SPP3 & 0.773 & & \\
\hline SPP4 & 0.868 & & \\
\hline BUREK1 & 0.782 & \\
\hline BUREK2 & 0.296 & \\
\hline BUREK3 & 0.801 & \\
\hline BUREK4 & 0.776 & 0.664 & \\
\hline FD1 & & 0.739 & \\
\hline FD2 & 0.836 & 0.756 \\
\hline FD3 & 0.858 & 0.706 \\
\hline FD4 & & \\
\hline KUAL1 & & \\
\hline KUAL2 & & \\
\hline KUAL3 & & \\
\hline KUAL4 & & \\
\hline
\end{tabular}

Sumber: Data Penelitian, 2020

Tabel 2

Nilai Cronbach's Alpha dan rho_A

\begin{tabular}{lcccc}
\hline & \multicolumn{2}{c}{ Cronbach's Alpha } & \multicolumn{2}{c}{ rho_A } \\
\hline & Nilai sebelum & Nilai setelah & Nilai sebelum & Nilai setelah \\
\hline X1 (SPP) & 0.868 & 0.868 & 0.885 & 0.885 \\
\hline X2 (BUREK) & 0.650 & 0.700 & 0.725 & 0.708 \\
\hline X3 (FD) & 0.788 & 0.788 & 0.829 & 0.829 \\
\hline Y1 (KUAL) & 0.719 & 0.719 & 0.724 & 0.724 \\
\hline
\end{tabular}

Sumber: Data Penelitian, 2020 


\section{Tabel 3}

Nilai Composite Reliability dan Average Variance Extracted (AVE)

\begin{tabular}{lcccc}
\hline & \multicolumn{2}{c}{ Composite Reliability } & \multicolumn{2}{c}{ Average Variance Extracted (AVE) } \\
\hline & Nilai sebelum & Nilai setelah & Nilai sebelum & Nilai setelah \\
\hline X1 (SPP) & 0.908 & 0.908 & 0.713 & 0.713 \\
\hline X2 (BUREK) & 0.774 & 0.830 & 0.486 & 0.620 \\
\hline X3 (FD) & 0.859 & 0.859 & 0.606 & 0.606 \\
\hline Y1 (KUAL) & 0.825 & 0.825 & 0.541 & 0.541 \\
\hline \multicolumn{5}{c}{ Sumber: Data Penelitian, 2020 }
\end{tabular}

Pengukuran Internal Consistency Reliability dalam penelitian tradisional biasanya menggunakan nilai Cronbach's Alpha sebagai acuan, jika nilai $>0,80$ adalah skala yang baik, $=0,70$ adalah skala yang dapat diterima. Selain dengan Cronbach's Alpha, Internal Consistency Reliability dapat diukur menggunakan Composite Realibility, dibandingkan Cronbach's Alpha, Composite Reliability dipandang para peneliti dapat memberikan perkiraan reabilitas yang lebih baik karena memperhitungkan bahwa indikator memiliki beban yang berbeda. (G. David Garson, 2016). Untuk dapat dikatakan suatu item pernyataan reliabel, nilai Composite Reliability harus $>0,7$, dalam tahap awal penelitian (Henseler et al., 2009). Dari tabel 2 dan tabel 3, diketahui Internal Consistency Reliability dari tiap variabel laten X1 (SPP), X2 (BUREK), X3 (FD), Y1 (KUAL), baik diukur melalui nilai Cronbach's Alpha maupun nilai Composite Realibility-nya telah berada $>0.7$, sehingga hasil uji menyatakan bahwa model telah memenuhi uji Internal Consistency Reliability.

Suatu instrument dikatakan valid apabila mampu mengukur apa yang diukur, karena suatu alat ukur yang valid mempunyai validitas yang tinggi. PLS SEM memiliki dua uji validitas yaitu validitas konvergen dan validitas diskriminan. Untuk menguji validitas konvergen setiap variabel laten, dapat dilakukan dengan menggunakan nilai rata-rata varian yang diekstraksi (Average Variance Extracted/AVE), nilai yang diharapkan >0.5 yang berarti sebuah variabel laten dapat menjelaskan lebih dari setengah varian indikatornya secara rata-rata (Ken Kwong-Kay Wong, 2013) (Henseler et al., 2009). Pada hasil penelitian di tabel 3, nilai AVE telah $>0.5$, sehingga setiap variabel dalam penelitian yaitu X1 (SPP), X2 (BUREK), X3 (FD), Y1 (KUAL), telah memenuhi uji validitas konvergen.

Validitas diskriminan digunakan untuk mengukur suatu variabel laten berbagi varian lebih dengan indikator yang mendasarinya daripada dengan variabel-variabel laten lainnya dalam model yang sama. Validitas diskriminan dapat diukur dengan menggunakan kriteria Fornell-Larckell, jika akar kuadrat dari AVE di setiap variabel laten > dari nilai korelasi di antara variabel laten lainnya maka dapat diartikan variabel laten tersebut telah memiliki validitas diskriminan yang baik (Ken Kwong-Kay Wong, 2013) (Hulland, 1999). Selain menurut kriteria Fornell-Larcker, validitas diskriminan juga dapat diukur menggunakan Cross Loading Factor. Cross loading menilai nilai loading pada konstruk yang dituju harus lebih besar dibandingkan dengan nilai loading dengan konstruk yang lain (Henseler et al., 2009). 
Tabel 4

Kriteria Fornell-Lacker

\begin{tabular}{lrccc}
\hline & X1 (SPP) & X2 (BUREK) & X3 (FD) & Y1 (KUAL) \\
\hline X1 (SPP) & $\mathbf{0 . 8 4 4}$ & & & \\
\hline X2 (BUREK) & 0.320 & $\mathbf{0 . 7 8 7}$ & & \\
\hline X3 (FD) & 0.266 & 0.321 & $\mathbf{0 . 7 7 8}$ & \\
\hline Y1 (KUAL) & 0.431 & 0.444 & 0.429 & $\mathbf{0 . 7 3 5}$ \\
\hline
\end{tabular}

Sumber: Data Penelitian, 2020

Tabel 5

Kriteria Cross Loading

\begin{tabular}{lrcrc}
\hline & X1 (SPP) & X2 (BUREK) & X3 (FD) & Y1 (KUAL) \\
\hline SPP1 & $\mathbf{0 . 8 9 3}$ & 0.200 & 0.220 & 0.341 \\
\hline SPP2 & $\mathbf{0 . 8 3 8}$ & 0.396 & 0.161 & 0.313 \\
\hline SPP3 & $\mathbf{0 . 7 7 3}$ & 0.256 & 0.293 & 0.456 \\
\hline SPP4 & $\mathbf{0 . 8 6 8}$ & 0.228 & 0.180 & 0.284 \\
\hline BUREK1 & 0.313 & $\mathbf{0 . 7 8 9}$ & 0.354 & 0.410 \\
\hline BUREK2 & 0.257 & $\mathbf{0 . 7 9 4}$ & 0.209 & 0.270 \\
\hline BUREK3 & 0.175 & $\mathbf{0 . 7 7 9}$ & 0.165 & 0.339 \\
\hline FD1 & 0.223 & 0.260 & $\mathbf{0 . 6 6 4}$ & 0.232 \\
\hline FD2 & 0.273 & 0.240 & $\mathbf{0 . 7 3 9}$ & 0.254 \\
\hline FD3 & 0.257 & 0.251 & $\mathbf{0 . 8 3 6}$ & 0.402 \\
\hline FD4 & 0.117 & 0.263 & $\mathbf{0 . 8 5 8}$ & 0.396 \\
\hline KUAL1 & 0.349 & 0.325 & 0.287 & $\mathbf{0 . 7 3 9}$ \\
\hline KUAL2 & 0.405 & 0.375 & 0.294 & $\mathbf{0 . 7 5 6}$ \\
\hline KUAL3 & 0.218 & 0.285 & 0.256 & $\mathbf{0 . 7 0 6}$ \\
\hline KUAL4 & 0.270 & 0.311 & 0.415 & $\mathbf{0 . 7 3 9}$ \\
\hline
\end{tabular}

Sumber: Data Penelitian, 2020

Berdasarkan hasil pada tabel 4 dan 5, diketahui variabel laten telah memiliki validitas diskriminan yang baik berdasarkan kriteria Fornell-Larcker dan cross loading.

Analisa inner model dilakukan untuk memastikan bahwa model struktural yang dibangun robust dan akurat, hal ini dilakukan setelah memastikan pengujian outer model telah reliabel dan valid (Henseler et al., 2009). Uji koefisien jalur merupakan nilai besarnya hubungan atau pengaruh variabel eksogen terhadap variabel endogen, dilakukan menggunakan prosedur Bootrapping (Henseler et al., 2009). Dalam bootstrap, sejumlah besar sampel diambil dari sampel asli dengan dilakukan penggantian. Penggantian dilakukan dengan mengambil secara acak melalui populasi sampel, sampel yang telah diambil memiliki peluang untuk diambil lebih dari satu kali atau bahkan tidak ikut terambil sama sekali dalam satu kali tahap obeservasi (Hair Jr et al., 2017). Uji koefisien jalur pada penelitian ini menggunakan uji T (2-tailed) dengan tingkat signifikansi 5\% dengan 500 subsample, dimana koefisien jalur dinilai signifikan bila nilai $\mathrm{t}_{\text {statistik }}>\mathrm{t}_{\text {kritis }}$ yaitu 1.960 dan nilai $\mathrm{P}<0,05$. Nilai koefisien jalur dari hasil penelitian diperoleh sebagai berikut: 
Tabel 6

Path Coefficients

\begin{tabular}{lccccc}
\hline & $(\mathrm{O})$ & $(\mathrm{M})$ & $(\mathrm{STDEV})$ & T Statistics & P Values \\
\hline $\mathrm{X} 1$ (SPP) -> Y1 (KUAL) & 0.273 & 0.262 & 0.083 & 3.285 & 0.001 \\
\hline X2 (BUREK) -> Y1 (KUAL) & 0.270 & 0.274 & 0.061 & 4.427 & 0.000 \\
\hline X3 (FD) -> Y1 (KUAL) & 0.270 & 0.300 & 0.102 & 2.656 & 0.008 \\
\hline & Sumber: Data Penelitian, 2020
\end{tabular}

\section{A. Pengaruh Implementasi Kebijakan Penentuan Sasaran terhadap Kualitas Pemeriksaan Pajak}

Berdasarkan hasil penelitian yang diperoleh dapat diketahui bahwa semakin baik implementasi kebijakan penentuan sasaran prioritas pemeriksaan maka semakin tinggi kualitas hasil pemeriksaan pajak, telah dinyatakan terbukti kebenarannya, karena hasil penelitian memperoleh nilai $\mathrm{t}_{\text {statistik }}>$ nilai $\mathrm{t}_{\text {kritis }}(1.960)$ dan nilai $\mathrm{P}<$ 0,05, yang menunjukkan adanya pengaruh positif signifikan implementasi kebijakan penentuan sasaran prioritas pemeriksaan terhadap variabel laten kualitas hasil pemeriksaan sebesar 0,273 atau $27,3 \%$. Hal ini menunjukkan melalui revitalisasi proses bisnis pemeriksaan dengan melakukan pemilihan terhadap wajib pajak yang diperiksa secara objektif, transparan, tepat sasaran dan berdasarkan pada kriteriakriteria pemilihan yang dapat diandalkan, memberikan pengaruh positif signifikan terhadap kualitas hasil pemeriksaan pajak lingkup Kanwil DJP Bali.

Efektifitas pemilihan wajib pajak yang akan diperiksa (effective audit case selection) akan menimbulkan persepsi positif pada wajib pajak karena wajib pajak yang patuh mempunyai risiko diperiksa lebih kecil dibandingkan dengan wajib pajak yang tidak patuh. Di sisi lain, pemeriksaan menjadi lebih efisien karena hanya fokus pada wajib pajak yang tidak patuh. Hasil penelitian ini senada dengan penelitian yang dikemukakan oleh Rotich, Kiprop \& Nzioki (2019, p. 73) diketahui bahwa proses seleksi audit adalah faktor yang mempengaruhi efektivitas pemeriksaan pajak di wilayah South Rift Valley Region. Seleksi dalam melakukan pemeriksaan merupakan hal penting dalam melaksanakan pemeriksaan pajak, dimana penelitian tersebut merekomendasikan bahwa perlu perbaikan prosedur pemilihan kasus audit yang dapat diterapkan pada wajib pajak besar di sektor formal dan pembayar pajak kecil di sektor informal di wilayah peneltian tersebut. Penelitian lain oleh Haifa Ainur, dkk (2016, p. 7) mengungkap hal yang serupa dalam penelitian diketahui bahwa banyaknya wajib Pajak yang diperiksa diakibatkan kurang selektifnya proses pemilihan atas wajib pajak yang diperiksa. Hal ini merupakan hambatan yang dapat mempengaruhi efektifitas jalannya pemeriksaan pajak. Hal ini didukung juga oleh penelitian oleh Alm, Blackwell and McKee (2004, p. 226) yang meneliti terkait aturan seleksi pemeriksaan Pajak Penjualan di Amerika Serikat dan dampaknya terhadap kepatuhan pajak. Secara keseluruhan, diketahui jika negara-negara mengikuti strategi seleksi pemeriksaan pajak yang sistematis dan mengetahui sumber-sumber ketidakpatuhan yang potensial, maka langkah tersebut 
juga dapat mengatasi beberapa potensi ketidakefisienan yang disebabkan oleh basis pajak yang sempit, dan memiliki potensi untuk meningkatkan pendapatan.

\section{B. Pengaruh Implementasi Kebijakan Akses Informasi Keuangan terhadap Kualitas Pemeriksaan Pajak}

Berdasarkan hasil penelitian yang diperoleh dapat diketahui bahwa semakin baik implementasi kebijakan akses informasi keuangan untuk kepentingan perpajakan maka semakin tinggi kualitas hasil pemeriksaan pajak, telah dinyatakan terbukti kebenarannya, karena hasil penelitian menunjukkan adanya pengaruh positif signifikan implementasi kebijakan akses informasi keuangan terhadap variabel laten kualitas hasil pemeriksaan sebesar 0,270 atau 27,0\% ditandai dengan nilai $\mathrm{t}_{\text {statistik }}>$ nilai $\mathrm{t}_{\text {kritis }}(1.960)$ dan nilai $\mathrm{P}<0,05$.

Hal ini menunjukkan bahwa dengan ditetapkannya kebijakan yang mengatur akses informasi keuangan untuk kepentingan perpajakan, maka kegiatan pemeriksaan akan dapat dilaksanakan dengan lebih efektif, efisien dan berkualitas karena didukung oleh ketersediaan informasi keuangan yang akurat dan dapat diandalkan, sehingga dapat diartikan Implementasi Kebijakan Akses Informasi Keuangan untuk Kepentingan Perpajakan, yang pada penelitian ini ditandai dengan: LJK, LJK Lainnya, dan/atau Entitas Lain memberikan informasi dan atau bukti atau keterangan terkait rekening keuangan, informasi keuangan yang diberikan oleh LJK, LJK lainnya, dan/atau Entitas lain kepada pihak Direktorat Jenderal Pajak telah sesuai, data jawaban informasi dan atau bukti atau keterangan yang diberikan LJK, LJK Lainnya, dan/atau Entitas Lain dapat dimanfaatkan dalam rangka menghasilkan ketetapan yang dapat diandalkan, memberikan pengaruh positif signifikan terhadap kualitas hasil pemeriksaan pajak lingkup Kanwil DJP Bali.

Hasil penelitian ini senada dengan penelitian yang dikemukakan oleh Endah P. S dan Erik Nugraha (2018, p. 93) diperoleh bahwa kebijakan akses informasi keuangan terhadap perilaku wajib pajak dan implikasinya terhadap variabel kepatuhan wajib pajak secara bersama-sama (simultan) atau dapat diartikan bahwa terdapat pengaruh kebijakan akses informasi keuangan terhadap perilaku wajib pajak dan berimplikasi terhadap kepatuhan wajib pajak. Kepatuhan wajib pajak dapat didefinisikan sebagai suatu keadaan dimana wajib pajak memenuhi semua kewajiban perpajakan dan melaksanakan hak perpajakannya (Widodo, 2010, p. 69).

Penelitian lain oleh (George \& Diavastis, 2015) dengan tujuan untuk mengetahui faktor signifikan yang memberikan kontribusi dalam peningkatan efektifias pemeriksaan pajak, khususnya mereka menggarisbawahi pentingnya peranan teknologi dan undang-undang hukum bagi kinerja pemeriksa pajak, hal tersebut dapat membantu pemeriksa pajak untuk mendeteksi pelanggaran dengan lebih baik.

Berdasarkan hasil survei yang dimuat dalam laporan OECD yang dipublikasi oleh Committee on Fiscal Affairs (CFA) (2000, p. 45) tersebut mengungkapkan bahwa sebagian besar negara-negara di dunia memiliki akses yang besar terhadap 
informasi bank untuk keperluan administrasi pajak dan untuk tujuan pertukaran informasi. Berdasarkan laporan OECD (OECD, 2000), akses terhadap informasi bank dapat meningkatkan kemampuan otoritas pajak untuk secara efektif mengelola undang-undang perpajakan yang disahkan oleh parlemen mereka. Informasi yang mungkin perlu diperoleh otoritas pajak dari bank untuk kasus-kasus tertentu adalah informasi tentang setoran dan penarikan. Informasi bank penting bagi otoritas pajak sehubungan dengan verifikasi kewajiban pajak wajib pajak dan untuk penagihan kewajiban pajak.

\section{Pengaruh Pelaksanaan Forensik Digital untuk Kepentingan Perpajakan terhadap Kualitas Hasil Pemeriksaan Pajak}

Berdasarkan hasil penelitian yang diperoleh dapat diketahui bahwa semakin baik pelaksanaan forensik digital maka semakin tinggi kualitas hasil pemeriksaan pajak, telah dinyatakan terbukti kebenarannya, karena hasil penelitian menunjukkan adanya pengaruh positif signifikan pelaksanaan forensik digital terhadap variabel laten kualitas hasil pemeriksaan sebesar 0,270 atau 27,0\% ditandai dengan nilai $\mathrm{t}_{\text {statistik }}>$ nilai $\mathrm{t}_{\text {kritis }}(1.960)$ dan nilai $\mathrm{P}<0,05$.

Forensik digital berkaitan dengan kualitas pemeriksaan, dimana proses forensik memiliki kemampuan untuk dapat mendeteksi manipulasi laporan yang dilakukan dalam rangka penipuan pajak, seperti yang diperoleh berdasarkan hasil penelitian oleh Khersiat (2018, pp. 145-153) yang bertujuan untuk memberikan penekanan perlunya akuntan forensik untuk mendeteksi manipulasi laporan keuangan dan memerangi penipuan pajak di Yordania.

Berdasarkan hasil penelitian diketahui akuntan forensik memiliki peranan untuk mendeteksi tax fraud dalam laporan keuangan, diperoleh nilai signifikan level 0.00 yang lebih kecil dari 0.05 yang mengindikasikan terdapat pengaruh signifikan forensik akuntan untuk mendeteksi manipulasi angka dalam laporan keuangan. Direkomendasikan dalam penelitian tersebut, agar Income Tax Department memiliki akuntan forensik dalam rangka pengamanan penerimaan negara. Rekomendasi serupa juga diperoleh dalam penelitian oleh Oyedokun (2017, pp. 1-22), Auditor pajak dan penyelidik pajak harus dilengkapi dengan undang-undang perpajakan, ilmu akuntansi pajak, dan teknik-teknik dalam audit dan investigasi yang akan membantu mereka dalam mendapatkan bukti yang dapat diterima yang cocok untuk menambah pertanggungjawaban pajak tambahan. Otoritas pajak harus meningkatkan kesempatan tersebut dengan membangun kapasitas para auditor pajak untuk menangani meningkatnya kasus penghindaran pajak dan penggelapan pajak.

Penelitian oleh Susanto, Mulyani, Aziz dan Sukmadilaga memperoleh hasil bahwa (2019, pp. 252-267) kompetensi auditor secara langsung memiliki efek positif pada tingkat deteksi kecurangan; forensik digital juga secara langsung memiliki efek positif pada tingkat deteksi penipuan, sehingga semakin tinggi dukungan forensik digital dapat meningkatkan level deteksi penipuan. 
Pengaruh Kebijakan Pemeriksaan, Kebijakan Akses Informasi Keuangan dan Forensik Digital Terhadap Kualitas Pemeriksaan Pajak

\section{Kesimpulan}

Berdasarkan temuan penelitian diperoleh bahwa implementasi kebijakan penentuan sasaran prioritas pemeriksaan, implementasi kebijakan buka rekening dan pelaksanaan forensik digital berpengaruh positif signifikan terhadap kualitas pemeriksaan dalam lingkup Kanwil DJP Bali. 


\section{BIBLIOGRAFI}

Asnawi, M. (2013). The Impact of Audit Rate, Perceived Probability of Audit on Tax Compliance Decision: A Laboratory Experiment Study). Jurnal Ekonomi \& Bisnis Indonesia (Fakultas Ekonomi Dan Bisnis Universitas Gadjah Mada), 28(2), 286301. https://doi.org/10.22146/jieb.29763

Aspexsia, A. P. (2018). Pengaruh Pemeriksaan Pajak Terhadap Kepatuhan Wajib Pajak di Indonesia. Universitas Gadjah Mada.

D’Agosto, E., Manzo, M., Pisani, S., \& D'Arcangelo, F. M. (2018). The Effect of Audit Activity on Tax Declaration: Evidence on Small Businesses in Italy. Public Finance Review, 46(1), 29-57. https://doi.org/10.1177/1091142117698035

Darma, G. (2006). the Impact of Information Technology Investment on the Hospitality Industry. In Maksi (Vol. 6, pp. 1-22).

Direktorat Jenderal Pajak. (2017). SE-36/PJ/2017 tentang Pedoman Forensik Digital Untuk Kepentingan Pajak (SE-36/PJ/2017).

Direktorat Jenderal Pajak. (2018). SE-15/PJ/2018 Tentang Kebijakan Pemeriksaan (SE15/PJ/2018). Direktorat Jenderal Pajak.

Endah Purnama Sari, E. N. (2018). Perilaku Kepatuhan Wajib Pajak. 8(1), 81-96.

G. David Garson. (2016). Partial Least Squares (PLS-SEM):Regression \& Structural Equation Models.

George, D. S., \& Diavastis, I. (2015). Tax audit effectiveness in Greek firms: Tax auditors perceptions. Journal of Accounting and Taxation, 7(7), 123-130. https://doi.org/10.5897/jat2015.0186

Hair Jr, J. F., Hult, G. T. M., Ringle, C., \& Sarstedt, M. (2017). A primer on partial least squares structural equation modeling (PLS-SEM) (Second Edi). Sage publications.

Henseler, J., Ringle, C. M., \& Sinkovics, R. R. (2009). The use of partial least squares path modeling in international marketing. Advances in International Marketing, 20, 277-319. https://doi.org/10.1108/S1474-7979(2009)0000020014

Hulland, J. (1999). Strategic Management Journal. 1. Strategic Management Journal, 20(2), 195-204.

James Alm, Michael Mckee, C. B. (2004). Audit Selection and Firm Compliance with a Broad- based Sales Tax. April 2019. https://doi.org/10.2139/ssrn.897314

Ken Kwong-Kay Wong. (2013). Partial Least Squares Structural Equation Modelling (PLS-SEM) Techniques Using SmartPLS. Marketing Bulletin, 24. 
Khersiat, O. M. (2018). The Role of the Forensic Accountant in the Detection of Tax Fraud in Financial Statements: A Survey Study in the Jordanian Accounting and Auditing Offices and Firms. International Journal of Economics and Finance, 10(5), 145. https://doi.org/10.5539/ijef.v10n5p145

Lo, B., \& Darma, C. S. (2000). Employee Perception of the Impact of Information Technology Investment in Organisations: a survey of the hotel industry. Australasian Journal of Information Systems, 7(2 SE-Research Articles). https://doi.org/10.3127/ajis.v7i2.275

Mebratu, A. A. (2016). Impact of Tax Audit on Improving Taxpayers Compliance: Emperical Evidence from Ethiopian Revenue Authority at Federal Level. International Journal of Accounting Research, 2(12), 1-19. https://doi.org/10.12816/0033279

Modugu, K. P., \& Anyaduba, J. O. (2014). Impact of tax audit on tax compliance in Nigeria. International Journal of Business and Social Science, 5(9), 207-215.

OECD. (2000). Improving Access to Bank Information for Tax Purposes. Improving Access to Bank Information for Tax Purposes. https://doi.org/10.1787/9789264181267-en

OECD. (2006). Strengthening Tax Audit Capabilities: General Principles and Approaches. Oecd, 54(October).

Oyedokun, G. E. (2017). Imperatives of Tax Audit and Investigation for Revenue Generation in Nigeria. SSRN Electronic Journal, January 2016. https://doi.org/10.2139/ssrn.2913151

Palil, M., \& Mustapha, A. F. (2011). Determinants of tax compliance in Asia: A case of Malaysia. European Journal of Social Sciences, 24, 7-32.

Pemerintah Republik Indonesia, R. I. (2017). Peraturan Pemerintah Pengganti Undang-Undang Republik Indonesia Nomor 1 Tahun 2017 Tentang Akses Informasi Keuangan untuk Kepentingan Perpajakan (PERATURAN PEMERINTAH NOMOR 1 TAHUN 2017; Issue 95).

Rahim, H. A., Topowijono, S. N. (2016). Analisis Efektivitas Pelaksanaan Pemeriksaan Pajak Atas Penerbitan Surat Ketetapan Pajak. Jurnal Perpajakan (JEJAK), 10(1), $1-8$.

Republik Indonesia, R. I. (2007). Penjelasan atas Undang-Undang Republik Indonesia Nomor 28 Tahun 2007 Tentang Perubahan Ketiga Atas Undang-Undang Nomor 6 Tahun 1983 Tentang Ketentuan Umum Dan Tata Cara Perpajakan (UndangUndang Republik Indonesia Nomor 28 Tahun 2007).

Rotich, C. C., Kiprop, S. K., \& Nzioki, P. M. (2019). The effect of audit case selection on tax audit effectiveness in south rift valley region, Kenya. 69-75. 
Luh Putu Dian Shavitri H. dan Gede Sri Darma

Sugiyono. (2011). Metode Penelitian Kuantitatif. Alfabeta.

Susanto, H., Mulyani, S., Azis, H. A., \& Sukmadilaga, C. (2019). The level of fraud detection affected by auditor competency using digital forensic support. Utopia y Praxis Latinoamericana, 24(Extra5), 252-267.

Widodo, W. (2010). Moralitas, budaya, dan kepatuhan pajak. Alfabeta. 